\title{
Physiological and Pathological Functions of CARD9 Signaling in the Innate Immune System
}

\author{
Larsen Vornholz and Jürgen Ruland
}

\section{Contents}

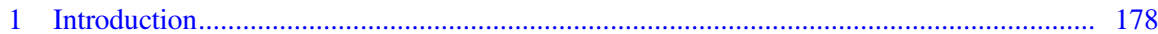

2 CARD9 Structure, Expression and Binding Partners ................................................ 179

3 CARD9 Activation and Innate CBM Complex Assembly ......................................... 179

4 Effector Functions of CARD9 Signaling …….............................................................. 181

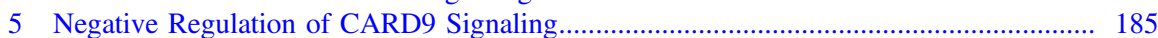

6 Physiological Functions of CARD9 Signaling in Host Protection ................................... 186

6.1 CARD9 Signaling in Antifungal Immunity ........................................................ 186

6.2 CARD9 in Antibacterial Defense.................................................................... 188

6.3 CARD9 in Immunity to Parasites ................................................................... 189

6.4 CARD9 Signaling upon Viral Recognition .......................................................... 189

7 CARD9 Signaling in Noninfectious Inflammation and Cancer Models ............................ 190

8 Genetic Alterations of CARD9 in Human Disease......................................................... 192

9 Conclusions and Therapeutic Perspective................................................................... 194

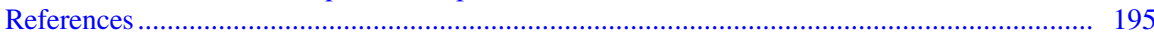

L. Vornholz $\cdot$ J. Ruland $(\bowtie)$

TUM School of Medicine, Institute of Clinical Chemistry and Pathobiochemistry, Technical University of Munich, 81675 Munich, Germany

e-mail: j.ruland@tum.de

TranslaTUM, Center for Translational Cancer Research, Technical University of Munich, 81675 Munich, Germany

J. Ruland

German Cancer Consortium (DKTK), Heidelberg, Germany

German Center for Infection Research (DZIF), Munich Partner Site, Munich, Germany

Current Topics in Microbiology and Immunology (2020) 429: 177-203

https://doi.org/10.1007/82_2020_211

(C) Springer Nature Switzerland AG 2020

Published Online: 16 May 2020 


\begin{abstract}
Caspase recruitment domain protein 9 (CARD9) forms essential signaling complexes in the innate immune system that integrate cues from C-type lectin receptors and specific intracellular pattern recognition receptors. These CARD9-mediated signals are pivotal for host defense against fungi, and they mediate immunity against certain bacteria, viruses and parasites. Furthermore, CARD9-regulated pathways are involved in sterile inflammatory responses critical for immune homeostasis and can control pro- and antitumor immunity in cancer microenvironments. Consequently, multiple genetic alterations of human CARD9 are connected to primary immunodeficiencies or prevalent inflammatory disorders in patients. This review will summarize our current understanding of CARD9 signaling in the innate immune system, its physiological and pathological functions and their implications for human immune-mediated diseases.
\end{abstract}

\title{
1 Introduction
}

The cells of the innate immune system make up our first line of defense against microbial pathogens, and they mediate homeostasis of the organism upon tissue damage. To mediate these effects, innate immune cells utilize germline-encoded pattern recognition receptors (PRRs) such as C-type lectin receptors (CLRs) to sense pathogen-associated molecular patterns (PAMPs) or endogenous danger-associated molecular patterns (DAMPs) (Gong et al. 2020; Rivera et al. 2016). The controlled activation of PRR-associated intracellular signaling pathways is critical for immune physiology and for host protection, and pathological dysfunctions of the same pathways are frequent causes of human immunodeficiencies and inflammatory disorders (Cao 2016; Huber-Lang et al. 2018; Zhang and Cao 2019).

Caspase recruitment domain protein 9 (CARD9) is a central signaling adapter molecule in the innate immune system. This protein integrates signals from the C-type lectin receptor and plays a very prominent role downstream of the antifungal CLRs Dectin-1, Dectin-2 and Mincle (Gross et al. 2006; Robinson et al. 2009; Shenderov et al. 2013). In addition, CARD9 can be activated by several intracellular nucleic acid-sensing PRRs and NOD-like receptors (Hsu et al. 2007; Poeck et al. 2010; Roth et al. 2014), and it controls innate immune responses to fungi, certain bacteria, viruses and parasites and is also involved in sterile danger pathways upon cellular damage (Brown et al. 2018). These CARD9-controlled pathways are highly relevant to human immune pathology, as genetic alterations of CARD9 are causal for primary immunodeficiencies (Drummond and Lionakis 2016) or risk factors for prevalent human inflammatory disorders (Drummond et al. 2018). CARD9 has also been reported to play critical roles in tumor immune microenvironments (Bergmann et al. 2017; Wang et al. 2018; Zhong et al. 2019). In the next chapters, we discuss our current understanding of the molecular regulation of CARD9 signaling with a focus on CLR pathways and outline the known physiological and pathological functions of CARD9 signaling in human disease. 


\section{CARD9 Structure, Expression and Binding Partners}

The CARD9 protein has a bipartite structure consisting of an amino-terminal caspase recruitment domain (CARD) (Bertin et al. 2000), which represents a homotypic protein-protein interaction module that can associate with other CARDs, and a carboxy-terminal coiled-coil region that serves as an oligomerization site (Bertin et al. 2000) (Fig. 1a). CARD9 is highly conserved between mice and humans, sharing approximately $87 \%$ similarity and $83 \%$ identity. CARD 9 is specifically expressed in myeloid cells of the innate immune system, such as dendritic cells, macrophages and neutrophils, and is found in various tissues, including the spleen, liver, brain, placenta, peripheral blood and bone marrow (Bertin et al. 2000; Hsu et al. 2007; Roth and Ruland 2013). Initial studies have demonstrated that CARD9 can utilize its CARD to directly interact with the ubiquitously expressed CARD-containing adapter protein B-cell lymphoma 10 (BCL10) (Bertin et al. 2000). BCL10 in turn is constitutively associated with the multifunctional protein mucosa-associated lymphoid tissue lymphoma translocation protein 1 (MALT1), which is composed of a death domain, three immunoglobulin (Ig)-like domains and a catalytic caspase-like domain (Fig. 1a), which has proteolytic function. MALT1 is therefore also referred to as a paracaspase and is unique to the mammalian proteome (Uren et al. 2000). Activation of CARD9 by innate immune signals also leads to rapid activation of the BCL10-MALT1 module and the formation of a CARD9-BCL10-MALT1 complex (also called the CBM complex), which then mediates context-dependent inflammatory responses (Fig. 1b, c). The BCL10-MALT1 module can also be activated by a series of additional immune and inflammatory receptors in other cell types, including antigen receptors in $\mathrm{T}$ and $\mathrm{B}$ lymphocytes, via CARD11 (Ruland and Hartjes 2019).

\section{CARD9 Activation and Innate CBM Complex Assembly}

The activation of CARD9 is a highly regulated process that can be triggered by multiple and potentially all SYK-coupled CLRs, including Dectin-1 (Gross et al. 2006), Dectin-2 (Robinson et al. 2009) and Mincle (also known as CLEC4E) (Shenderov et al. 2013) (Fig. 1b). CARD9 is also activated by other ITAM-containing receptors on myeloid cells, including the Fc $\gamma$ receptor Fc $\gamma$ RIII, myeloid-associated immunoglobulin-like receptor II (MAIR-II) (also known as CD300D), osteoclast-associated immunoglobulin-like receptor (OSCAR) and triggering receptor expressed on myeloid cells 1 (TREM1) (Hara et al. 2007) (Fig. 1b). Furthermore, the cytosolic nucleic acid sensors retinoic acid-inducible gene 1 (RIG-I), melanoma differentiation-associated protein 5 (MDA5, also known as IFIH1) (Poeck et al. 2010) and RAD50 (Roth et al. 2014) as well as nucleotide-binding oligomerization domain-containing protein 2 (NOD2) (Hsu et al. 2007) can utilize CARD9 for signal transduction (Fig. 1c). 


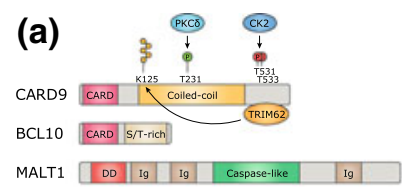

(b)

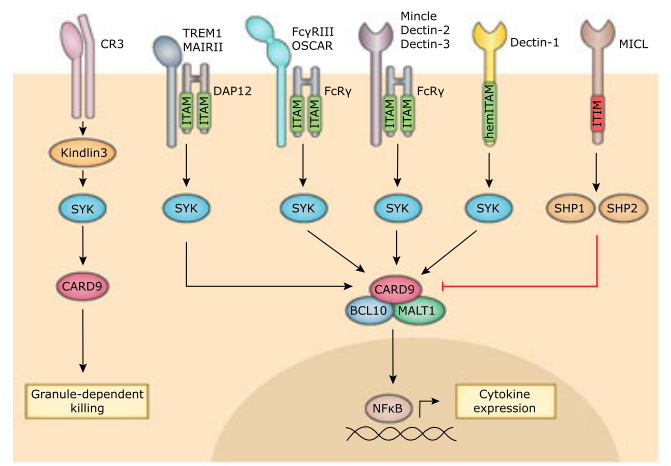

(c)

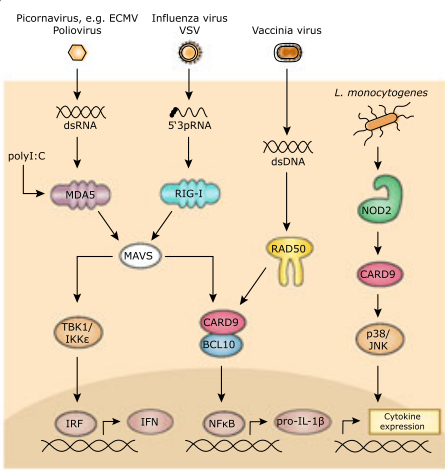

Fig. 1 CARD9-BCL10-MALT1 complex and signaling. a In myeloid cells, the CBM signalosome consists of CARD9-BCL10-MALT1. CARD9 has a bipartite structure with a CARD domain at the amino-terminal end and a coiled-coil domain at the carboxy-terminal end. TRIM62 binds CARD9 at its C-terminal end and is required for K125 ubiquitylation. Activating phosphorylation at T231 is mediated by PKCd, whereas inhibitory phosphorylation at T531/T533 is mediated by CK2. BCL10 consists of amino-terminal CARD and a serine-/threonine-rich carboxy-terminal region. MALT1 comprises an amino-terminal death domain (DD), three immunoglobulin-like (Ig) domains and a caspase-like catalytic domain. b Upon extracellular DAMPs/PAMPs (e.g., fungi), CARD9 relays signals from SYK-coupled immunoreceptor tyrosine-based activation motif (ITAM)-containing CLRs such as Dectin-1 and ITAM-associated CLRs such as Dectin-2, Dectin-3 and Mincle, which lack a cytoplasmic ITAM domain and thus require ITAM-containing adaptor proteins such as DAP12 or FcR $\gamma$ for signal transduction. Further, ITAM-associated receptors engaging CARD9 are the $\mathrm{Fc} \gamma$ receptor Fc $\gamma$ RIII, myeloid-associated immunoglobulinlike receptor II (MAIR-II, CD300D), osteoclast-associated immunoglobulin-like receptor (OSCAR) and triggering receptor expressed on myeloid cells 1 (TREM1). In contrast, the immunoreceptor tyrosine-based inhibition motif (ITIM)-bearing myeloid inhibitory C-type lectin-like receptors (MICLs) generally suppress inflammatory pathways by recruiting tyrosine phosphatases such as SHP1 and SHP2. Alternatively, unopsonized fungi can be sensed via complement receptor 3 (CR3), which leads to granule-dependent fungal killing via Kindlin3/SYK/ CARD9. c CARD9 is also activated by intracellular pathogens of bacterial or viral origin. The cytosolic nucleic acid sensors RIG-I and MDA5 and the DNA double-strand break repair protein RAD50 promote NF- $\mathrm{KB}$ signaling via CARD9, which leads to inflammatory cytokine expression (e.g., IL-1 $\beta$ ), cellular activation and selective adaptive immunity. Furthermore, CARD9 mediates p38/ERK activation upon NOD2 engagement of intracellular bacteria

To date, the activation of CARD9 in the CLR pathways in the context of fungal recognition is best understood (Fig. 2). The early activation of CLRs, such as Dectin-1, Dectin-2 or Mincle, leads to Src family tyrosine kinase-mediated phosphorylation of immunoreceptor tyrosine-based activation motifs (ITAMs), 
ITAM-like regions within Dectin-1 or Dectin-2, or Mincle at associated transmembrane ITAM adapters, such as the Fc receptor $\gamma$-chain or DAP10 (Geijtenbeek and Gringhuis 2009; Rogers et al. 2005; Sato et al. 2006; Yamasaki et al. 2008). These receptor proximal events result in the recruitment of SYK to receptors and their activation, leading to the activation of PKC $\delta$ (Strasser et al. 2012) in cooperation with VAV proteins (Roth et al. 2016). Active PKC $\delta$ then triggers direct phosphorylation of CARD9 within its coiled-coil domain at position T231, and this modification is critical to induce assembly of the CARD9-BCL10-MALT1 complex (Strasser et al. 2012). Structural analysis revealed that CBM assembly upon CARD9 activation requires disruption of its autoinhibitory state, which leads to a conformational change that exposes CARD9-CARD for BCL10 binding (Holliday et al. 2019). CARD9-BCL10 interactions are then mediated via CARDs, whereby CARD9-CARD forms a helical assembly that serves as a template for unidirectional filamentous BCL10 polymerization, presumably dependent on $\mathrm{Zn}^{2+}$ (Holliday et al. 2018).

The assembled CBM complex in innate immune cells serves subsequently as a scaffold structure that likely places ubiquitin modifiers and protein kinases such as TAK1 in proximity for downstream signaling (Strasser et al. 2012). Although the precise collection of interaction partners in the CARD9-controlled innate immune pathways remains to be identified, the BCL10-MALT1 module can in principle recruit the E2 ubiquitin-conjugating enzymes UBC13 and UEV1a (Deng et al. 2000; Sun et al. 2004), the E3 ubiquitin ligases tumor necrosis factor (TNF) receptor-associated factor 2 (TRAF2) and TRAF6 (Oeckinghaus et al. 2007; Sun et al. 2004), cellular inhibitor of apoptosis protein 1 (cIAP1) and cIAP2 (Yang et al. 2016a), and the linear ubiquitin chain assembly complex (LUBAC) (Yang et al. 2016b). These factors have been reported to regulate BCL10-MALT1-dependent lymphocyte signaling (Ruland and Hartjes 2019). It is therefore conceivable that similar mechanisms would also control CARD9-BCL10-MALT1 signaling for innate immunity. Ubiquitylation reactions at CARD9-BCL10-MALT1 signalosomes are expected to recruit ubiquitin-binding proteins such as TAK1-binding protein 2 (TAB2) and TAB3 and for recruitment of TGF $\beta$-associated kinase 1 (TAK1) (Sun et al. 2004; Wang et al. 2001) to activate downstream pathways. Nevertheless, the exact regulation of individual CARD9 effectors upon CARD9 activation by distinct PRRs is still insufficiently resolved.

\section{Effector Functions of CARD9 Signaling}

One key output of activated CARD9-BCL10-MALT1 signalosomes is activation of the canonical NF- $\kappa$ B signaling pathway (Roth and Ruland 2013) involving TAK1 and activation of the I $\kappa \mathrm{B}$ kinase- $\beta$ (IKK $\beta$ ) (Fig. 2). This mechanism is particularly important for the control of the transcriptionally active NF- $\kappa \mathrm{B}$ subunits RelA/p65 and c-Rel (Hayden and Ghosh 2012; Liu et al. 2017), which are essential for orchestrating the expression of a large series of inflammatory cytokines, such as 


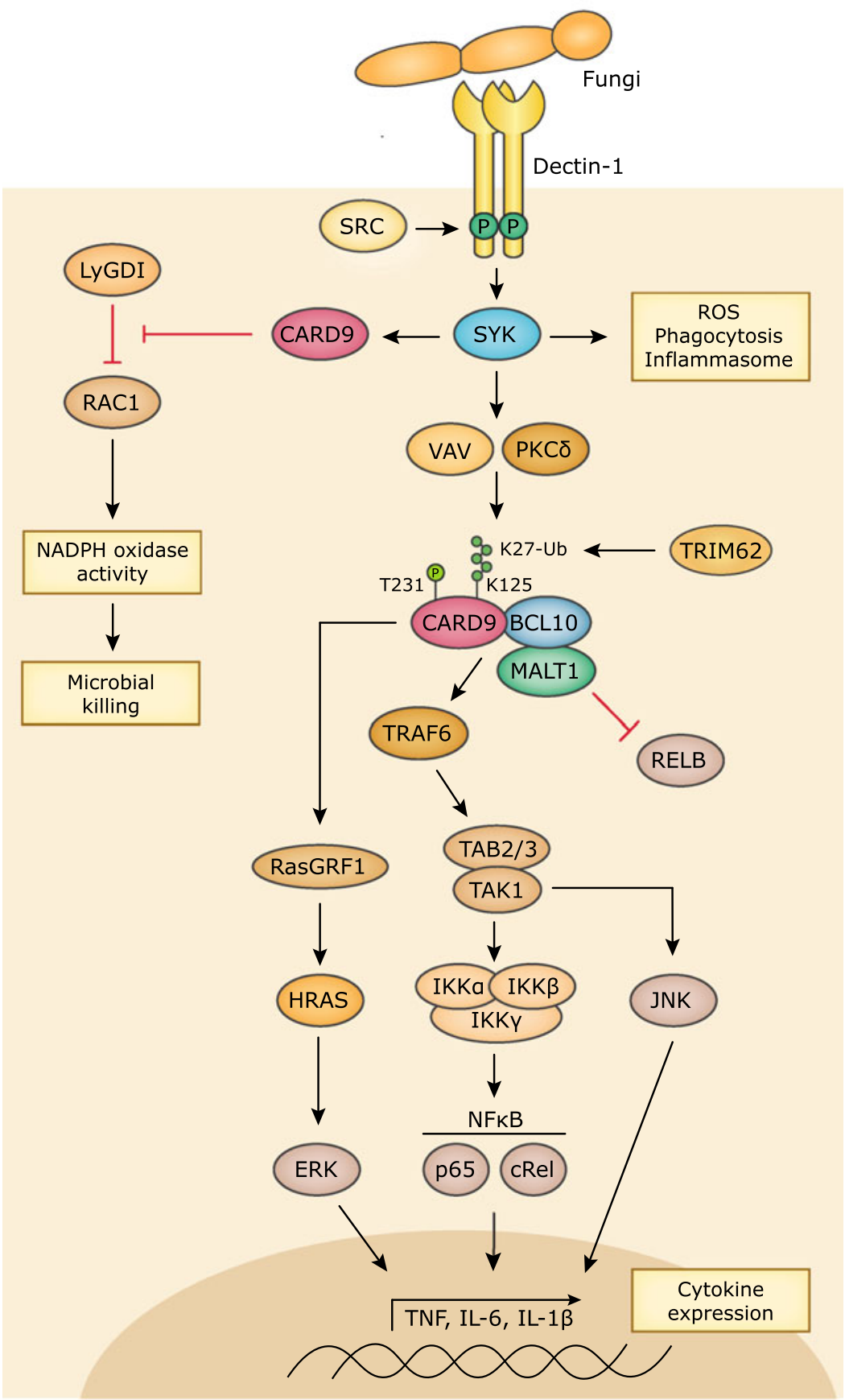


4Fig. 2 CARD9 effector functions. After fungal engagement of CLRs (such as Dectin-1), the Src family kinase member Src phosphorylates the intracellular ITAM domain, allowing the recruitment of SYK. SYK subsequently activates the protein kinase C delta (PKC $\delta$ ), which phosphorylates CARD9 at T231 in the coiled-coil domain in cooperation with VAV proteins, allowing CBM complex assembly. Subsequent K27-linked polyubiquitination of CARD9 at K125 by TRIM62 is required for NF- $\mathrm{KB}$ activation. Additionally, TRAF6 is recruited to the CBM signalosome upon assembly to mediate its ubiquitination. Then, the IKK complex is recruited to the CBM complex and activated by TAK1 together with TAB2 and TAB3. Activated IKK phosphorylates I $\mathrm{K} \mathrm{B} \alpha$ to induce proteasomal degradation, releasing the NF-kB subunits $\mathrm{p} 65$ and c-Rel for nuclear translocation and subsequent inflammatory cytokine expression. Additionally, TAK1 activates JNK. The NF- $\mathrm{BB}$ subunit RELB is counter-regulated by MALT1-mediated cleavage. Independent of BCL10/MALT1, Dectin-1 engagement initiates SYK-dependent Ras-GRF1 phosphorylation, which complexes with CARD9 and subsequently activates the H-Ras/ERK pathway. Moreover, CARD9 inhibits LyGDI-mediated suppression of RAC1, allowing NADPH oxidase activity, which is needed for microbial killing in the phagolysosome. For details, see text

TNF, IL-1 $\beta$, IL-6, IL-10, IL-12, IL-23 and GM-CSF, and chemokines, such as CCL3, CXCL1, CXCL2 and CXCL8, which can be induced upon CARD9 engagement (Drummond et al. 2015; Gavino et al. 2016; Gross et al. 2006; Jhingran et al. 2015; LeibundGut-Landmann et al. 2007; Németh et al. 2016; Poeck et al. 2010; Roth et al. 2014). To drive full NF- $\kappa B$ activation, CARD9 recruits the ubiquitin ligase TRIM62, which binds to the C-terminal tail of CARD9 and mediates K27-linked ubiquitination of CARD9 at K125 (Cao et al. 2015). This ubiquitin-conjugating modification sterically disrupts the autoinhibitory state of the CARD9 CARD-coiled-coil interface, enabling BCL10 polymerization and subsequent NF- $\kappa$ B activation (Holliday et al. 2019). CARD9 signaling is also implicated in CLR-induced ERK (Jia et al. 2014) and in NOD2-induced p38 and JNK signaling (Hara et al. 2007), which further contribute to fully inducing the inflammatory cascade.

Triggering of the CARD9-BCL10-MALT1 complex induces activation of MALT1 protease function ( $\mathrm{Yu}$ et al. 2015). Although the specific role of MALT1-mediated proteolysis in CARD9-dependent innate immunity is still ill-defined, nine MALT1 substrates have been identified thus far, largely in activated T cells (Ruland and Hartjes 2019). The currently known MALT1 substrates include MALT1 itself and BCL10, the cleavage of which is thought to serve as a feedback loop to support optimal gene transcription (Baens et al. 2014). Furthermore, MALT1 can cleave and thereby inactivate the negative NF- $\kappa \mathrm{B}$ and MAPK regulators A20 (Coornaert et al. 2008) and CYLD (Staal et al. 2018) as well as HOIL1 (Douanne et al. 2016; Elton et al. 2016; Klein et al. 2015) to amplify the NF- $\kappa \mathrm{B}$ and JNK pathways. Similarly, upon lymphocyte activation, MALT1 can cleave the ribonuclease Regnase 1 (also known as ZC3H12A) (Uehata et al. 2013) or the mRNA decay regulators Roquin 1 (also known as RC3H1) and Roquin 2 (also known as RC3H2) (Jeltsch et al. 2014), which are important for controlling the stability of inflammatory mRNAs by binding to common stem-loop elements in their 3' untranslated region (3'-UTR) (Mino et al. 2015). Although A20 (Coornaert 
et al. 2009), CYLD (Zhang et al. 2011), HOIL1 (MacDuff et al. 2017), Regnase 1 (Mao et al. 2017) or Roquin 1/2 (Athanasopoulos et al. 2016) are also involved in the regulation of innate immune responses, it is currently unknown whether and under what conditions MALT1 may inactivate these factors during CARD9-controlled innate immunity. Nevertheless, the fact that MALT1 cleaves overlapping substrates in innate immune cells and in activated lymphocytes is demonstrated in the case of the NF- $\kappa \mathrm{B}$ subunit RELB that is inactivated in stimulated T cells (Hailfinger et al. 2011) as well as in myeloid lineage cells upon CARD9-mediated Dectin-1 signaling (Xu et al. 2018). The NF- $\kappa B$ RELB subunit acts primarily in the noncanonical $\mathrm{NF}-\kappa \mathrm{B}$ pathway and controls upon Dectin-1 stimulation the expression of the Th-2 cytokine IL-5, which is an important example of how CARD9-triggered MALT1 proteolysis tunes the inflammatory response.

In addition to the activation of CARD9-BCL10-MALT1 complexes, CARD9 has also been reported to engage other immune effector pathways. In response to Dectin-1-initiated SYK-mediated Ras-GRF1 phosphorylation, CARD9 can associate with Ras-GRF1 to activate the H-Ras/ERK pathway for the full induction of inflammatory cytokines such as IL-6, TNF and IL-1 $\beta$ (Jia et al. 2014). Moreover, CARD9 can control the production of ROS under certain conditions. Upon phagocytosis of Listeria monocytogenes, CARD9 is recruited to bacteria-containing phagolysosomes and suppresses the LyGDI-mediated inhibition of Rac1, enabling guanine nucleotide exchange factors (GEFs) to fuel Rac1 with GTP, which in turn drives NADPH complex-dependent ROS production required for antimicrobial killing (Wu et al. 2009). Furthermore, CARD9 can mediate granule-dependent killing of unopsonized fungal species that are recognized by complement receptor 3 (CR3) (Gazendam et al. 2014, 2016) through mechanisms that remain to be further defined.

In response to cytosolic PRR engagement, CARD9 plays additional selective roles. After the activation of NOD2, CARD9 selectively activates the MAP kinases

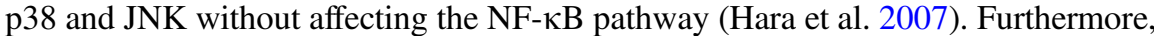
in response to cytosolic RNA or DNA detection by the nucleic acid receptors RIG-I, MDA5 (Poeck et al. 2010) or RAD50 (Roth et al. 2014), CARD9 engages BCL10 presumably without MALT1 to drive canonical NF- $\kappa B$ signaling for the production of inflammatory cytokines, particularly IL-1 $\beta$.

To induce the production of IL-1 $\beta$ during innate immunity, CARD9 frequently collaborates with the activation of inflammasomes (Gross et al. 2009; Poeck et al. 2010), which are multiprotein complexes that induce caspase-1 activation to cleave pro-IL-1 $\beta$ and related cytokines into their bioactive form (Guo et al. 2015). While CARD9 is not directly involved in the assembly of inflammasome complexes, it mediates pro-IL-1 $\beta$ expression as well as NF- $\kappa \mathrm{B}$-dependent inflammasome priming in response to fungal cell wall components (e.g., $\beta$-glucan) (Gross et al. 2009), mycobacterial glycolipids (e.g., TDM) (Schweneker et al. 2013; Shenderov et al. 2013) and viral nucleic acids (e.g., 3pRNA) (Poeck et al. 2010). Recent work has also reported that CARD9 can associate with necroptosis-inducing kinases RIPK1 and RIPK3 to regulate myeloid cell necroptosis upon fungal infection (Cao et al. 
2019). While these noncanonical functions of CARD9 are currently emerging, putative BCL10-MALT1-independent mechanisms of CARD9 during cytosolic PRR signaling, ROS or necroptosis control are still insufficiently defined.

\section{Negative Regulation of CARD9 Signaling}

To dampen or downregulate CARD9 signaling to counter-regulate inflammation, the innate immune system has developed several mechanisms that operate at different levels of the signaling cascade (Fig. 3). In addition to ITAM-containing activating CLRs that activate CARD9, myeloid cells also express inhibitory CLRs that contain immunoreceptor tyrosine-based inhibition motives (ITIMs), such as the myeloid inhibitory C-type lectin-like receptor MICL (Redelinghuys and Brown 2011). These ITIM CLRs can recruit protein tyrosine phosphatases such as SHP1 and SHP2 to negatively regulate SYK-induced cellular activation (Marshall et al. 2004) and, consequently, CARD9 engagement. An additional mechanism that counteracts activating CLR signaling involves the E3 ubiquitin ligase CBLB (Wirnsberger et al. 2016; Xiao et al. 2016), which is active during antifungal immunity. CBLB mediates ubiquitin-dependent degradation of Dectin-1 and Dectin-2 as well as SYK, resulting in the negative regulation of CARD9 signaling (Wirnsberger et al. 2016; Xiao et al. 2016).

Direct negative regulation of the CARD9-BCL10-MALT1 complex itself is mediated by the regulator of autophagosome maturation and endocytosis called Rubicon (Yang et al. 2012). In response to fungal PAMPs or RNA viruses, Rubicon switches its interaction from the phosphoserine-/phosphothreonine-binding protein 14-3-3 $\beta$ to CARD9 and thereby induces the disassembly of CARD9-BCL10-MALT1 complexes as an inhibitory feedback for CBM signaling in response to CLR and RIG-I ligands (Yang et al. 2012). Here, the $S_{248}$ phosphorylation status of Rubicon in its ST-N region is critical for selective 14-3-3 $\beta$ or CARD9 binding.

CARD9 is also negatively regulated by phosphorylation-dependent events. In this context, casein kinase 2 (CK2) can directly phosphorylate the c-terminus of CARD9 at T531/T533 and mediate subsequent negative regulation of the NF- $\kappa \mathrm{B}$ pathway via the von Hippel-Lindau tumor suppressor protein (pVHL) (Yang et al. 2007). However, whether pVHL can directly bind CARD9 or requires an accessory protein remains unclear. Downstream of kinase 3 (DOK3) can induce protein phosphatase (PP)1-dependent dephosphorylation of CARD9 at threonine residues, which subsequently attenuates CARD9-dependent NF- $\mathrm{KB}$ and JNK activation, and the subsequent reduction in cytokine production results in negatively regulated neutrophil antifungal immunity (Loh et al. 2019). Moreover, it is conceivable that additional inhibitory phosphorylation or the inhibition of activating phosphorylation and physical interference with activating binding partners or selective degradation of CARD9 complex components could further negatively regulate this pathway, although these hypotheses have been less studied. 


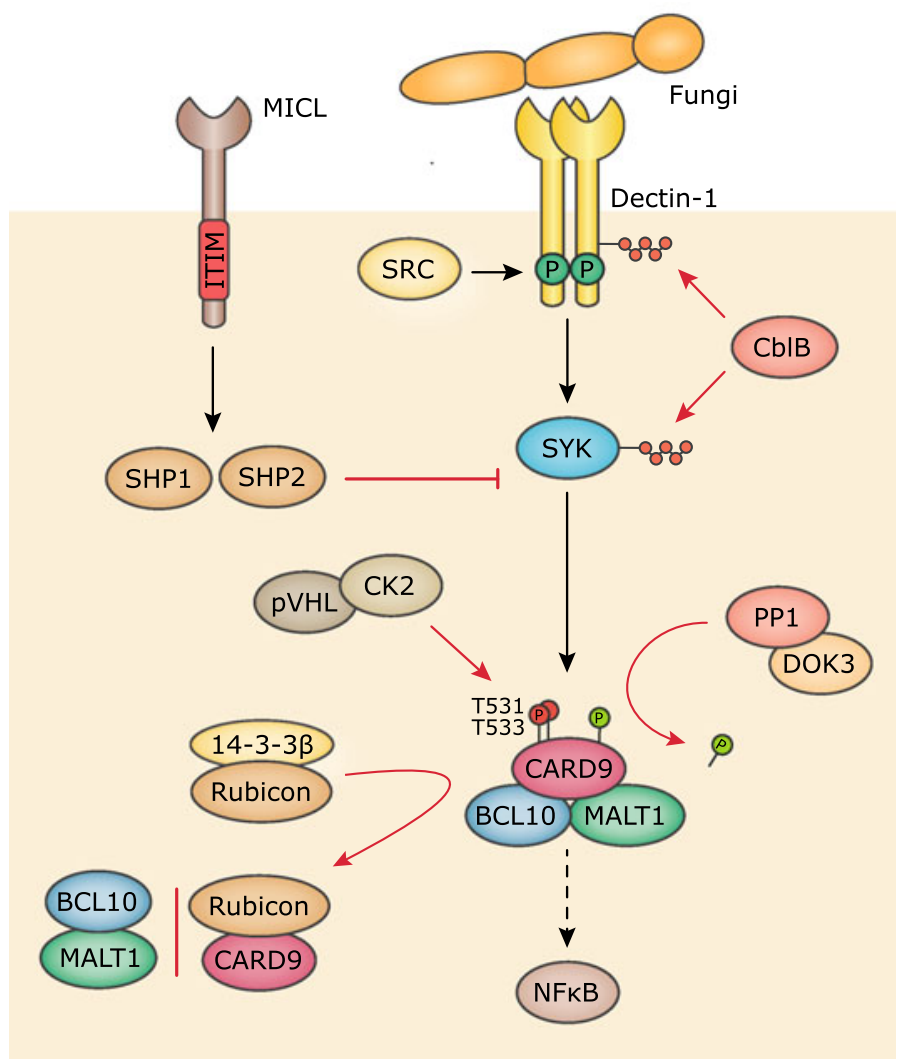

Fig. 3 Negative regulation of CARD9 signaling. ITIM-containing CLRs such as MICL recruit SHP1/SHP2 to generally inhibit SYK-mediated activating receptor signaling. Serving as inhibitory feedback, Rubicon switches its interaction from 14-3-3 $\beta$ to CARD9 upon stimulation and thereby induces disassembly of the CBM complex. Via pVHL, CK2 can directly phosphorylate the c-terminus of CARD9 at T531/T533 and mediate subsequent negative regulation of NF- $\mathrm{KB}$. Dephosphorylation of CARD9 by DOK3-induced PP1 activity can further attenuate NF- $\mathrm{B}$ signaling. CARD9 signaling during antifungal immunity is further counter-regulated by CBLB-mediated degradation of Dectin-1 and Dectin-2 and their associated SYK kinase

\section{Physiological Functions of CARD9 Signaling in Host Protection}

\subsection{CARD9 Signaling in Antifungal Immunity}

The nonredundant functions of CARD9 in innate immunity and antifungal defense were originally discovered in studies of CARD9-deficient mice using Candida albicans infections as a model (Gross et al. 2006). Subsequent investigations demonstrated that CARD9 signaling also mediates host protection against 
Aspergillus fumigatus (Jhingran et al. 2012), Coccidioides posadasii (Hung et al. 2016), Microsporum canis (Mao et al. 2014), Phialophora verrucosa (Wu et al. 2016) and Cryptococcus neoformans (Yamamoto et al. 2014), which together establish CARD9 as one of the most important regulators of the mammalian antifungal immune response. These functions can be explained by the nonredundant role of CARD9 downstream of the SYK-coupled CLRs Dectin-1, Dectin-2, Dectin-3 and Mincle and the role of these receptors in sensing the fungal PAMPs $\beta$-glucan (Dectin-1) (Taylor et al. 2007), $\alpha$-mannans (Dectin-2 and Dectin-3) (Saijo et al. 2010; Zhu et al. 2013) and $\alpha$-mannose (Mincle) (Bugarcic et al. 2008).

To mediate antifungal defense, CARD9 triggers at least two important immune effector functions (Fig. 4). On the one hand, CARD9 signaling in monocytes and microglia induces the production of GM-CSF and CXCL1, respectively, which initiates the recruitment of neutrophils to the site of fungal infections (Drummond et al. 2015, 2019; Gavino et al. 2016). Neutrophils are required for fungal phagocytosis and killing and for the subsequent clearance of pathogens. The failure of CARD9-deficient mice to produce GM-CSF results in impaired neutrophil recruitment and allows invasive fungal growth (Drummond et al. 2015; Gavino et al. 2016; Jhingran et al. 2015). In addition to these immediate innate immune effects, CARD9 signaling in antigen-presenting cells also couples innate immune sensing to the activation of $\mathrm{T}$ cell-mediated adaptive immunity and controls, in particular, the differentiation of Th1 and Th17 cells (LeibundGut-Landmann et al. 2007; Robinson et al. 2009; Saijo et al. 2010; Sokol et al. 2013). CARD9 drives the

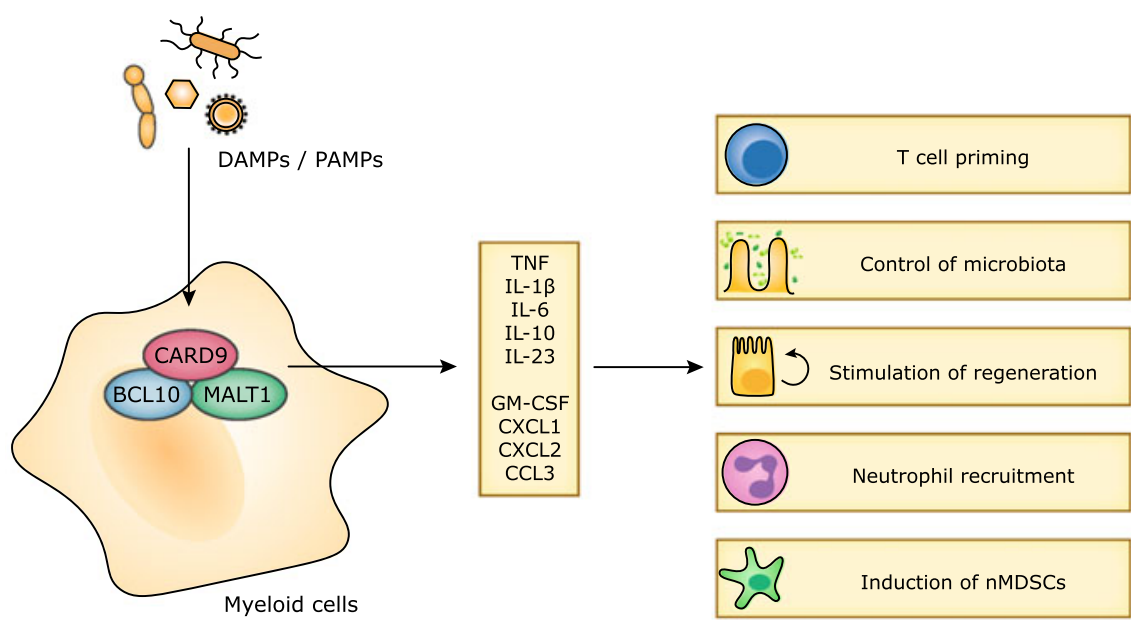

Fig. 4 Physiological functions of CARD9 in host defense and homeostasis. CARD9 signaling upon sensing DAMPs or PAMPs by myeloid cells leads to the expression of inflammatory cytokines and chemokines and presumably other effector molecules that orchestrate homeostatic and host defense function including $\mathrm{T}$ cell priming, control of the microbiota, stimulation of regeneration of epithelial cells, recruitment of neutrophils and the induction of neutrophilic myeloid-derived suppressor cells (nMDSCs). For details, see text 
production of a specific set of cytokines, including IL-1 $\beta$, IL-6 and IL-23, which provide a milieu that induces Th17 differentiation of antigen-stimulated naïve $\mathrm{T}$ cells (LeibundGut-Landmann et al. 2007; Saijo et al. 2010). Th17 cells are crucial for host defense against extracellular pathogens, including fungi such as Candida albicans (LeibundGut-Landmann et al. 2007) and Cryptococcus neoformans (Yamamoto et al. 2014). The failure of CARD9-deficient mice to mount adequate Th17 immunity is an additional cause of defective antifungal defense. During later phases of fungal infection, CARD9 regulates the development of neutrophilic myeloid-derived suppressor cells (nMDSCs) in a manner that depends on ROS, caspase-8 and IL-1 $\beta$ (Rieber et al. 2015). In general, nMDSCs can suppress $\mathrm{T}$ lymphocytes via ROS, arginase and NO to prevent pathological T cell and NK cell responses (Gabrilovich and Nagaraj 2009), and CARD9-mediated nMDSC generation after fungal recognition prevents tissue damage at later stages of infection.

\subsection{CARD9 in Antibacterial Defense}

Since CARD9-coupled CLRs sense not only fungi but also bacteria, it is not surprising that CARD9-deficient animals also exhibit pathological deficiencies in certain bacterial infection models. The mycobacterial cord factor trehalose-6,6-dimycolate (TMD) from M. tuberculosis is a potent proinflammatory PAMP detected by Mincle, and it induces potent CARD9-BCL10-MALT1 signaling (Shenderov et al. 2013; Werninghaus et al. 2009). This mechanism is particularly important for promoting the production of IL-10 during M. tuberculosis infection, which prevents neutrophil-mediated systemic hyperinflammation (Dorhoi et al. 2010). Furthermore, Mincle can mediate host protection against group A streptococcus (GAS) after recognition of the GAS-produced anchor of lipoteichoic acid monoglucosyldiacylglycerol (MDGD) by inducing the production of inducible nitric oxidase synthase (iNOS), ROS and inflammatory cytokines such as TNF, MIP-2 and IL-6, the latter of which is directly regulated by CARD9 (Imai et al. 2018). In the context of Vibrio cholerae infections, FcRg-CARD9 signaling induces inflammatory responses upon stimulation with the nontoxic cholera toxin subunit CTB (Phongsisay et al. 2015). Independent of CLRs, the ITAM-like motif bearing the CEACAM3 receptor engages the CARD9 pathway upon infection with Moraxella catarrhalis to induce the production of chemokines such as CXCL8 and CCL3 (Heinrich et al. 2016). The function of CARD9 in response to NOD2 stimulation has been implicated in the antibacterial defense against intracellular pathogens such as Listeria monocytogenes (Hsu et al. 2007). Moreover, CARD9-deficient animals are also hypersusceptible to bacterial infections with Citrobacter rodentium, which is commonly used to study experimental colitis (Lamas et al. 2018; Sokol et al. 2013). Linking innate to adaptive immunity, SYK-CARD9 signaling in APCs is also important for the optimal activation of T cells specific for bacterial proteins such as flagellin (Atif et al. 2015). 


\subsection{CARD9 in Immunity to Parasites}

Parasites such as Schistosoma mansoni, which are causative for human schistosomiasis (hepatic and intestinal granulomatous inflammation), are also detected by the SYK-coupled CLRs Dectin-2, Mincle and SIGNR5, which synergistically activate CARD9 for IL-1 $\beta$ and IL-23 production and subsequent Th17-mediated immunity (Kalantari et al. 2018; Ritter et al. 2010). The function of CARD9 is also required for host defense against the intracellular protozoan parasite Toxoplasma gondii by mediating IL-1 $\beta$ production in primary human peripheral blood monocytes (Pandori et al. 2019), presumably upon activation of Dectin-1 and Mincle (He et al. 2016; Yan et al. 2014). Furthermore, CARD9-mediated IL-1 $\beta$ production contributes to malaria-associated acute respiratory distress syndrome (ARDS) in response to Plasmodium falciparum, the most virulent species of malaria parasites (Maknitikul et al. 2017, 2018).

\subsection{CARD9 Signaling upon Viral Recognition}

Several SYK-coupled CLRs, such as DC-SIGN, langerin, MMR, DCIR, MDL-1 and LSECtin, have evolved to sense viruses such as HIV-1, HBV, influenza virus, measles virus, dengue virus and SARS corona virus (Geijtenbeek and Gringhuis 2009; Monteiro and Lepenies 2017), and it is therefore conceivable that these could signal via CARD9 during viral recognition. Furthermore, in vivo experiments with influenza virus (IFV) have demonstrated that CARD9-mediated innate activation plays a critical role in severe influenza pneumonia (Uematsu et al. 2015), presumably via DC-SIGN receptor engagement (Wang et al. 2008). In CARD9-deficient mice, pneumonia was drastically attenuated concomitant with reduced inflammatory cytokines and chemokines in the influenza-infected lungs. However, the type I interferon response and virus-specific adaptive lymphocyte immunity were not altered (Uematsu et al. 2015). Interestingly, CARD9 deficiency selectively altered the cytokine response to IFV in DCs in vitro but not in macrophages. Similarly, the Mincle-CARD9 signaling axis in DCs also controls the early antiviral response phase against the mosquito-transmitted La Crosse virus (LACV), whereas viral clearance was unaffected (Monteiro et al. 2019). Moreover, as indicated above, RNA and DNA viruses, which are detected by cytosolic nucleic acid sensors RIG-I, MDA5 (Poeck et al. 2010) and RAD50 (Roth et al. 2014), engage CARD9 for proinflammatory cytokine production. Consistently, RNA viruses such as vesicular stomatitis viruses (VSV) and DNA viruses such as vaccinia viruses (VV) activate CARD9 signaling in vitro, and deficiency of CARD9 results in impaired IL-1 $\beta$, TNF and IL-6 responses to these pathogens in vivo (Poeck et al. 2010). While these CARD9-dependent signals are important in 
shaping the $\mathrm{T}$ cell response to viruses at later stages of infection, they are not involved in the immediate early type I interferon responses that mediate innate antiviral protection.

\section{CARD9 Signaling in Noninfectious Inflammation and Cancer Models}

More recent experiments with CARD9-deficient mice have demonstrated critical functions for CARD9 signaling in the regulation of noninfectious immune homeostasis (Fig. 4). Using the classical inflammatory bowel disease (IBD) model of chemically induced colitis with dextran sodium sulfate (DSS) (Chassaing et al. 2014), CARD9-deficient animals were found to be hypersusceptible compared with wild-type animals (Bergmann et al. 2017). Mechanistic studies have demonstrated that CARD9 signaling in innate immune cells regulates the production of cytokines such as IL-6, TNF and IFN $\gamma$ and the Th17- and innate lymphoid cell (ILC)-related cytokines IL-17A, IL-17F and IL-22 during intestinal inflammation. These CARD9-induced cytokines are necessary to stimulate optimal IL-22 production by ILCs, which subsequently activate the IL-22 receptor on intestinal epithelial cells (IECs) to promote an epithelial regenerative response via STAT3 activation (Bergmann et al. 2017). Furthermore, CARD9 signaling shapes the composition of the gut microbiome (Lamas et al. 2016, 2018). Consequently, CARD9-deficient mice at baseline already exhibit an underrepresentation of bacterial species from the Adlercreutzia genus and Lactobacillus reuteri, which metabolize tryptophan into aryl hydrocarbon receptor (AHR) ligands, which are also crucial for the expression of IL-22 by lymphoid cells (Lamas et al. 2016). The impaired AHR ligand production is another reason for impaired IL-22 production and delayed epithelial regeneration in CARD9-deficient mice (Lamas et al. 2016). In line with the function of CARD9 in the antifungal response, the intestinal flora of CARD9-deficient mice also exhibits an aberrant fungal microbiome, which includes Candida tropicalis species that can increase the susceptibility to intestinal inflammation (Wang et al. 2018).

The effects of CARD9 signaling during intestinal inflammation have further consequences in models of colitis-associated cancer (CAC) (Bergmann et al. 2017; Hartjes and Ruland 2019; Malik et al. 2018; Wang et al. 2018). On the one hand, the CARD9-triggered IL-22-mediated proliferative IEC response can stimulate the growth of transformed colon epithelial cells and thereby enhance colon cancer growth (Bergmann et al. 2017). On the other hand, presumably dependent on the microbiota, CARD9 signaling can enhance granulocytic MDSC accumulation and activation in the lamina propria, which inhibits $\mathrm{T}$ cell-dependent antitumor immunity in the colon (Wang et al. 2018). Moreover, CARD9 signaling in the gut controls IL-18 production. This effect supports antitumor immunity during CAC development by promoting epithelial barrier integrity and by stimulating intestinal CD8 + T cells (Malik et al. 2018). 
While these recent studies have demonstrated that CARD9 signaling can mediate pro- and antitumor immune effects during CAC (Hartjes and Ruland 2019), CARD9 signaling not only affects colon cancer growth at the primary side but also contributes to liver metastasis of colon carcinoma cells by promoting metastasis-associated macrophage polarization in response to VEGF CARD9 engagement and by inducing the production of tumor-promoting cytokines such as IL-10 and IL-1 $\alpha$ (Yang et al. 2014). In addition to colon cancer, CARD9 has been implicated in the pathogenesis of renal cell carcinoma (RCC), whereby loss of the RCC tumor suppressor molecule pVHL leads to CARD9-BCL10-TRAF6-mediated signaling, which subsequently leads to oncogenic hyperactive JNK activation (An et al. 2013; Yang et al. 2007). In Lewis lung carcinoma, CARD9 has been implicated in regulating the accumulation of MDSCs in tumor tissues and subsequent IDO production, which can negatively regulate tumor growth $(\mathrm{Qu}$ et al. 2019). CARD9 has thus emerged as an important regulator of tumor immune microenvironments, although the cancer-derived ligands that can engage CARD9 signaling remain largely unclear.

Endogenous DAMPs that could in principle activate CARD9 include cholesterol crystals, SAP130 (a subunit of the histone deacetylase complex) and $\beta$-glucosylceramide (a ubiquitous intracellular metabolite that indicates massive tissue damage if elevated), which can all trigger Mincle (cholesterol crystals, $\beta$-glucosylceramide, SAP130) (Kiyotake et al. 2015; Nagata et al. 2017; Seifert et al. 2016) and vimentin (an intermediate filament protein), which activates Dectin-1 (vimentin) (Thiagarajan et al. 2013). While the in vivo scenarios under which these specific DAMPs activate CARD9 signaling are not well explored, there is emerging evidence that CARD9 signaling contributes to noninfectious inflammatory responses under conditions beyond the cancer microenvironment. In acute pancreatitis, the severity of pancreatic injury is correlated with overexpression of CARD9 in mononuclear cells, which leads to enhanced NF- $\kappa \mathrm{B}$ and p38 MAPK signaling-mediated cytokine expression that promotes inflammatory pathology (Yang et al. 2016c, 2017). In the context of ischemic heart disease, CARD9 signaling promotes neutrophil infiltration following the acute ischemia/reperfusion (I/ R) phase by inducing inflammatory cytokines such as TNF, IL-6, CXCL1 and MCP-1, thereby damaging the myocardium and promoting I/R injury (Qin et al. 2018). Similarly, after cerebral ischemic injury, which leads to an upregulation of triggering receptor expressed on myeloid cells (TREM)-1, the activation of CARD9 together with inflammasomes leads to pyroptosis and the release of inflammatory factors, which results in neuroinflammatory injury (Xu et al. 2019). Likewise, in a rat model of brain injury after subarachnoid hemorrhage (SAH), the sensing of necrotic cells by Mincle was linked to the activation of CARD9 signaling for inflammatory cytokine production, promoting neuroinflammation-induced brain damage following cerebral ischemia and reperfusion injury in the central nervous system (He et al. 2015). In contrast, in a murine model of atherosclerosis induced by a Western-type diet using $L d l r^{-/}$mice, CARD9 deficiency increased the atherosclerotic lesion size and severity, indicating that CARD9 signaling may be protective for the development of atherosclerosis (Thiem et al. 2019). Two 
additional studies demonstrated further critical functions of CARD9 during neutrophil-mediated sterile inflammatory pathology. These reports demonstrated that CARD9 signaling can drive autoantibody-induced rheumatoid arthritis and dermatitis by controlling inflammatory chemokine/cytokine release in neutrophils (Németh et al. 2016) and that CARD9 engages in cross talk with SHP-1 to regulate IL-1-driven neutrophilic footpad inflammation in an animal model of human neutrophilic dermatosis (Tartey et al. 2018). Thus, these studies demonstrate that CARD9 signaling can mediate critical pathophysiological responses during sterile inflammatory stress in several organ systems.

\section{Genetic Alterations of $C A R D 9$ in Human Disease}

Following the discovery of CARD9 as a nonredundant regulator of innate immunity and inflammation (Gross et al. 2006; Hara et al. 2007; Hsu et al. 2007) pathological CARD9 loss-of-function (LOF) mutations and CARD9 risk polymorphisms have been identified in human patients (Fig. 5). In line with the high susceptibility of CARD9-deficient mice to fungal infections (Gross et al. 2006), familial homozygous CARD9 LOF mutations in patients also result in a high susceptibility to fungal infections (Glocker et al. 2009). Since the report of autosomal recessive CARD9 LOF variants due to the Q295X mutation (Glocker et al. 2009), multiple CARD9 LOF mutations have been identified in patients (Drummond and Lionakis 2016), including the homozygous CARD9 missense mutations R18W (Lanternier et al. 2015a), R35Q (Lanternier et al. 2015b), R57H (Drummond et al. 2015), R70W (Lanternier et al. 2015b), Y91H (Gavino et al. 2014), R101C (Lanternier et al. 2013) and R101L (Grumach et al. 2015). All these alterations lead to impaired CARD9 signaling functions and a high susceptibility to fungal pathogens, including Candida albicans, Aspergillus fumigatus, Phialophora verrucosa, Corynespora cassiicola, several dermatophytes and some Trichophyton and Exophilia species, some of which cause lethal infections (Drummond and Lionakis 2016; Drummond et al. 2018). Candida infections are predominantly localized to the oral mucosa, subcutaneous tissues or the central nervous system (CNS), while Aspergillus, Exophilia and Phialophora species are recurrently detected in skin, CNS, abdominal organs or bone tissues (Drummond et al. 2018). Similar to CARD9-deficient mice, CARD9 signaling defects in patients lead to impaired Th17 cell responses (Glocker et al. 2009; LeibundGut-Landmann et al. 2007; Wang et al. 2014) and defective monocytic GM-CSF and C-X-C chemokine (e.g., CXCL1) production with impaired neutrophil recruitment to the site of infections (Drummond et al. 2015; Gavino et al. 2016).

In addition to $C A R D 9$ LOF mutations, multiple human $C A R D 9$ single-nucleotide polymorphisms (SNPs) have been associated with prevalent inflammatory disorders. These include IBDs, such as ulcerative colitis and Crohn's disease (Jostins et al. 2012; Rivas et al. 2011; Zhernakova et al. 2008) (McGovern et al. 2010) (Franke et al. 2010); ankylosing spondylitis, a severe form of arthritis affecting the 


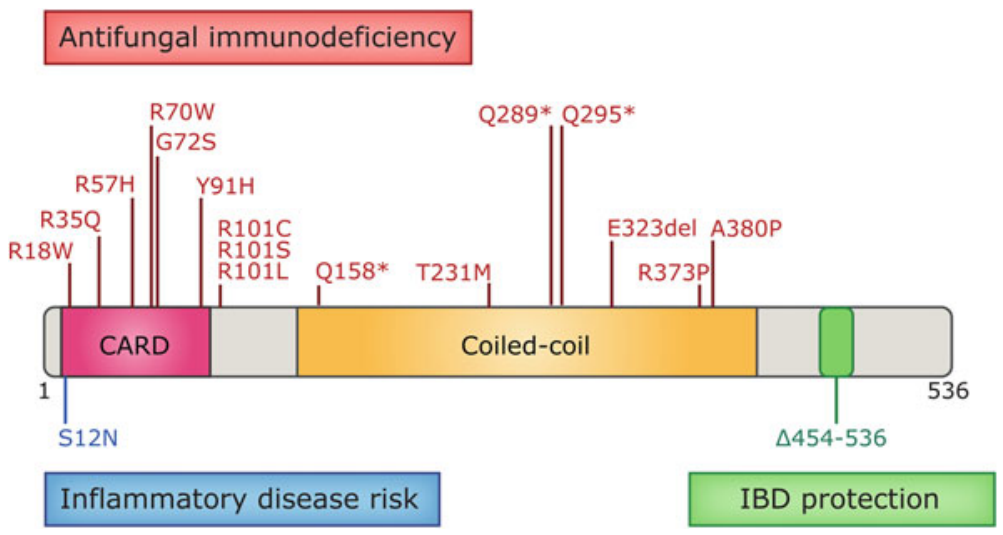

Fig. 5 Genetic alterations of CARD9 in human disease. While several CARD9 loss-of-function mutations lead to antifungal immunodeficiencies (red), the CARD9 ${ }^{\mathrm{S} 12 \mathrm{~N}}$ SNP leads to increased inflammatory disease risk (blue). Conversely, the CARD9 ${ }^{\Delta 11}$ variant, which results from a skipping of exon 11, has protective functions in IBD (green)

spine (Evans et al. 2011; Pointon et al. 2010); primary sclerosing cholangitis, a complex inflammatory disorder gradually resulting in liver cirrhosis (Janse et al. 2011); and IgA nephropathy, in which IgA deposits trigger glomerulonephritis leading to renal failure (Kiryluk et al. 2014). While most of the CARD9 disease SNPs do not affect the coding regions of CARD9, they presumably influence the level of CARD9 expression and thereby modulate CARD9 signaling strength. One prevalent CARD9 SNP, which is correlated with an increased risk for IBD, encodes a missense variant at position 12 where the asparagine $(\mathrm{N})$ is replaced by a serine (S) residue (Franke et al. 2010; McGovern et al. 2010). Experiments in knock-in mice that carry the respective $\mathrm{CARD} 9^{\mathrm{S} 12 \mathrm{~N}}$ allele demonstrated that this specific CARD9 variant can deviate CARD9 signaling to induce activation of the RELB NF- $\kappa B$ subunit for IL-5 production in response to CLR stimulation, resulting in a deviated $\mathrm{T}$ cell response toward Th2 differentiation (Xu et al. 2018). Consistently, human individuals with the $\mathrm{CARD} 9^{\mathrm{S} 12 \mathrm{~N}}$ variant exhibit an increased risk of Th2-mediated allergic bronchopulmonary fungal infections (Xu et al. 2018). Therefore, it is conceivable that related pathways might contribute to the inflammatory pathology in IBD patients with CARD $9^{\mathrm{S} 12 \mathrm{~N}}$ alteration.

Another human CARD9 IBD risk variant that has been functionally studied is the protective CARD9 isoform that decreases the risk of inflammatory bowel diseases and results from the exclusion of exon 11 within CARD9, creating a CARD $9^{\Delta 11}$ protein (Rivas et al. 2011). Mechanistically, CARD $9^{\Delta 11}$ can assemble trimeric signaling complexes with BCL10 and MALT1, but these CARD $9^{\Delta 11}$. BCL10-MALT1 complexes are defective in their ability to recruit TRIM62 for NF- $k B$ activation. Therefore, it has been suggested that a reduction in TRIM62-mediated inflammation underlies the protective function of CARD9 ${ }^{\Delta 11}$ in the intestinal immune system during IBD pathogenesis. While these investigations 
into the function of aberrant CARD9 signaling during intestinal inflammation provide the first insights into the role of these pathways in human inflammatory disorders, mechanistic studies on the function of CARD9 in ankylosing spondylitis, primary sclerosing cholangitis or IgA nephropathy have not yet been carried out.

\section{Conclusions and Therapeutic Perspective}

Over the last decade, the myeloid cell-specific adapter molecule CARD9 has emerged as a key regulator of innate immunity and inflammatory responses. Multiple human patients with CARD9 deficiency have been identified (Drummond and Lionakis 2016), and their primary immunodeficiency is a phenocopy of that observed in CARD9-deficient mice (Gross et al. 2006), confirming that CARD9 function is highly conserved between humans and mice. The recently developed mechanistic understanding of the CARD9 signaling pathways has paved the way for rational strategies for the treatment of CARD9-dependent innate immune disorders. On the one hand, patients with inherited CARD9 deficiencies and defective immune responses have been successfully reconstituted with allogeneic stem cell transplantation to reconstitute leukocyte-mediated CARD9 immunity, resulting in complete clinical remissions (Queiroz-Telles et al. 2019). Other patients with CARD9 mutations have been successfully treated with GM-CSF, because this

CARD9-controlled cytokine is critical for neutrophil recruitment and control of CNS candidiasis (Gavino et al. 2014). One additional strategy to enforce CLR-CARD9 signaling for the potential treatment of disseminated fungal infections could involve inhibition of the negative regulator CBLB, which has been experimentally tested in preclinical models (Wirnsberger et al. 2016; Xiao et al. 2016). Further strategies have been explored to boost CARD9-mediated immunity in vaccination regimens against mycobacterium tuberculosis (Ostrop et al. 2015), where selective triggering of the CLR-CARD9 signaling pathways with defined adjuvants can generate profound protective Th1 cell and Th17 cell responses (Werninghaus et al. 2009).

Conversely, in scenarios where aberrant CARD9 signaling might drive inflammatory pathologies, strategies are being developed to dampen the CARD9 pathway. Based on the knowledge that the IBD-protective CARD9 ${ }^{\Delta 11}$ protein exhibits impairment of TRIM62 recruitment and subsequent NF- $\kappa \mathrm{B}$ activation, small molecule inhibitors that disrupt the proinflammatory CARD9-TRIM62 interaction have been developed as candidate IBD therapeutics (Leshchiner et al. 2017). Other strategies to attenuate pathological CARD9 activity could potentially utilize MALT1 paracaspase inhibitors, which were initially developed for the treatment of malignant lymphomas that are driven by pathological BCL10-MALT1 signaling in transformed B lymphocytes (Ferch et al. 2009; Fontan et al. 2012; Hailfinger et al. 2011; Nagel et al. 2012). Although the functional identity and biological effects of MALT1 substrates in innate immune responses remain largely unclear, the activation of CARD9-BCL10-MALT1 signalosomes induces proteolytic activity of 
MALT1 (Gringhuis et al. 2011), which likely controls important inflammatory pathways. Therefore, it is necessary to further study the innate immune function of the MALT1 protease in vivo and to explore whether its pharmacological inhibition could also be utilized to target CARD9-mediated immune pathology. Therefore, further mechanistic knowledge on the regulation of CARD9-BCL10-MALT1 signaling complexes in innate immunity and inflammation is required; as such, knowledge will open new avenues for therapeutic strategies that target inflammatory pathways during human pathology.

Acknowledgements The work performed in the authors' laboratory was supported by research grants from the Deutsche Forschungsgemeinschaft (DFG, German Research Foundation) (SFB 1054/B01, Projektnummer 360372040 - SFB 1335/P01 and P08, Projektnummer 395357507 SFB 1371/P05, TRR 237/A10, RU 695/9-1) and the European Research Council (ERC) under the European Union's Horizon 2020 research and innovation program (grant agreement No 834154). We thank Lara Hartjes for her help developing the graphics.

\section{Declaration of Interests}

The authors declare no competing interests.

\section{References}

An J, Liu H, Magyar CE, Guo Y, Veena MS, Srivatsan ES, Huang J, Rettig MB (2013) Hyperactivated JNK is a therapeutic target in pVHL-deficient renal cell carcinoma. Cancer Res 73:1374-1385

Athanasopoulos V, Ramiscal RR, Vinuesa CG (2016) ROQUIN signalling pathways in innate and adaptive immunity. Eur J Immunol 46:1082-1090

Atif SM, Lee S-J, Li L-X, Uematsu S, Akira S, Gorjestani S, Lin X, Schweighoffer E, Tybulewicz VLJ, McSorley SJ (2015) Rapid CD4+ T-cell responses to bacterial flagellin require dendritic cell expression of Syk and CARD9. Eur J Immunol 45:513-524

Baens M, Bonsignore L, Somers R, Vanderheydt C, Weeks SD, Gunnarsson J, Nilsson E, Roth RG, Thome M, Marynen P (2014) MALT1 auto-proteolysis is essential for NF-KB-dependent gene transcription in activated lymphocytes. PLoS ONE 9:e103774

Bergmann H, Roth S, Pechloff K, Kiss EA, Kuhn S, Heikenwälder M, Diefenbach A, Greten FR, Ruland J (2017) Card9-dependent IL-1 $\beta$ regulates IL-22 production from group 3 innate lymphoid cells and promotes colitis-associated cancer. Eur J Immunol 47:1342-1353

Bertin J, Guo Y, Wang L, Srinivasula SM, Jacobson MD, Poyet JL, Merriam S, Du MQ, Dyer MJ, Robison KE et al (2000) CARD9 is a novel caspase recruitment domain-containing protein that interacts with BCL10/CLAP and activates NF-kappa B. J Biol Chem 275:41082-41086

Brown GD, Willment JA, Whitehead L (2018) C-type lectins in immunity and homeostasis. Nat Rev Immunol 18:374-389

Bugarcic A, Hitchens K, Beckhouse AG, Wells CA, Ashman RB, Blanchard H (2008) Human and mouse macrophage-inducible C-type lectin (Mincle) bind Candida albicans. Glycobiology 18:679-685

Cao X (2016) Self-regulation and cross-regulation of pattern-recognition receptor signalling in health and disease. Nat Rev Immunol 16:35-50

Cao Z, Conway KL, Heath RJ, Rush JS, Leshchiner ES, Ramirez-Ortiz ZG, Nedelsky NB, Huang H, Ng A, Gardet A et al (2015) Ubiquitin Ligase TRIM62 regulates CARD9-mediated anti-fungal immunity and intestinal inflammation. Immunity 43:715-726 
Cao M, Wu Z, Lou Q, Lu W, Zhang J, Li Q, Zhang Y, Yao Y, Zhao Q, Li M et al (2019) Dectin-1-induced RIPK1 and RIPK3 activation protects host against Candida albicans infection. Cell Death Differ

Chassaing B., Aitken JD, Malleshappa M, Vijay-Kumar M (2014) Dextran sulfate sodium (DSS)induced colitis in mice. Curr Protoc Immunol (Ed. John E Coligan Al 104, Unit-15.25)

Coornaert B, Baens M, Heyninck K, Bekaert T, Haegman M, Staal J, Sun L, Chen ZJ, Marynen P, Beyaert R (2008) T cell antigen receptor stimulation induces MALT1 paracaspase-mediated cleavage of the NF-kappaB inhibitor A20. Nat Immunol 9:263-271

Coornaert B, Carpentier I, Beyaert R (2009) A20: central gatekeeper in inflammation and immunity. J Biol Chem 284:8217-8221

Deng L, Wang C, Spencer E, Yang L, Braun A, You J, Slaughter C, Pickart C, Chen ZJ (2000) Activation of the IkappaB kinase complex by TRAF6 requires a dimeric ubiquitin-conjugating enzyme complex and a unique polyubiquitin chain. Cell 103:351-361

Dorhoi A, Desel C, Yeremeev V, Pradl L, Brinkmann V, Mollenkopf H-J, Hanke K, Gross O, Ruland J, Kaufmann SHE (2010) The adaptor molecule CARD9 is essential for tuberculosis control. J Exp Med 207:777-792

Douanne T, Gavard J, Bidère N (2016) The paracaspase MALT1 cleaves the LUBAC subunit HOIL1 during antigen receptor signaling. J Cell Sci 129:1775-1780

Drummond RA, Lionakis MS (2016) Mechanistic insights into the role of C-type lectin receptor/ CARD9 signaling in human antifungal immunity. Front Cell Infect Microbiol 6:39

Drummond RA, Collar AL, Swamydas M, Rodriguez CA, Lim JK, Mendez LM, Fink DL, Hsu AP, Zhai B, Karauzum H et al (2015) CARD9-dependent neutrophil recruitment protects against fungal invasion of the central nervous system. PLoS Pathog 11:e1005293

Drummond RA, Franco LM, Lionakis MS (2018) Human CARD9: a critical molecule of fungal immune surveillance. Front Immunol 9:1836

Drummond RA, Swamydas M, Oikonomou V, Zhai B, Dambuza IM, Schaefer BC, Bohrer AC, Mayer-Barber KD, Lira SA, Iwakura Y et al (2019) CARD9+ microglia promote antifungal immunity via IL-1 $\beta$ - and CXCL1-mediated neutrophil recruitment. Nat Immunol 20:559-570

Elton L, Carpentier I, Staal J, Driege Y, Haegman M, Beyaert R (2016) MALT1 cleaves the E3 ubiquitin ligase HOIL-1 in activated $\mathrm{T}$ cells, generating a dominant negative inhibitor of LUBAC-induced NF- $\kappa$ B signaling. FEBS J 283:403-412

Evans DM, Spencer CCA, Pointon JJ, Su Z, Harvey D, Kochan G, Oppermann U, Opperman U, Dilthey A, Pirinen M et al (2011) Interaction between ERAP1 and HLA-B27 in ankylosing spondylitis implicates peptide handling in the mechanism for HLA-B27 in disease susceptibility. Nat Genet 43:761-767

Ferch U, Kloo B, Gewies A, Pfänder V, Düwel M, Peschel C, Krappmann D, Ruland J (2009) Inhibition of MALT1 protease activity is selectively toxic for activated B cell-like diffuse large B cell lymphoma cells. J Exp Med 206:2313-2320

Fontan L, Yang C, Kabaleeswaran V, Volpon L, Osborne MJ, Beltran E, Garcia M, Cerchietti L, Shaknovich R, Yang SN et al (2012) MALT1 small molecule inhibitors specifically suppress ABC-DLBCL in vitro and in vivo. Cancer Cell 22:812-824

Franke A, McGovern DPB, Barrett JC, Wang K, Radford-Smith GL, Ahmad T, Lees CW, Balschun T, Lee J, Roberts R et al (2010) Genome-wide meta-analysis increases to 71 the number of confirmed Crohn's disease susceptibility loci. Nat Genet 42:1118-1125

Gabrilovich DI, Nagaraj S (2009) Myeloid-derived suppressor cells as regulators of the immune system. Nat Rev Immunol 9:162-174

Gavino C, Cotter A, Lichtenstein D, Lejtenyi D, Fortin C, Legault C, Alirezaie N, Majewski J, Sheppard DC, Behr MA et al (2014) CARD9 deficiency and spontaneous central nervous system candidiasis: complete clinical remission with GM-CSF therapy. Clin Infect Dis Off Publ Infect Dis Soc Am 59:81-84

Gavino C, Hamel N, Zeng JB, Legault C, Guiot M-C, Chankowsky J, Lejtenyi D, Lemire M, Alarie I, Dufresne S et al (2016) Impaired RASGRF1/ERK-mediated GM-CSF response characterizes CARD9 deficiency in French-Canadians. J Allergy Clin Immunol 137:11781188.e7 
Gazendam RP, van Hamme JL, Tool ATJ, van Houdt M, Verkuijlen PJJH, Herbst M, Liese JG, van de Veerdonk FL, Roos D, van den Berg TK et al (2014) Two independent killing mechanisms of Candida albicans by human neutrophils: evidence from innate immunity defects. Blood 124:590-597

Gazendam RP, van de Geer A, Roos D, van den Berg TK, Kuijpers TW (2016) How neutrophils kill fungi. Immunol Rev 273:299-311

Geijtenbeek TBH, Gringhuis SI (2009) Signalling through C-type lectin receptors: shaping immune responses. Nat Rev Immunol 9:465-479

Glocker E-O, Hennigs A, Nabavi M, Schäffer AA, Woellner C, Salzer U, Pfeifer D, Veelken H, Warnatz K, Tahami F et al (2009) A homozygous CARD9 mutation in a family with susceptibility to fungal infections. N Engl J Med 361:1727-1735

Gong T, Liu L, Jiang W, Zhou R (2020) DAMP-sensing receptors in sterile inflammation and inflammatory diseases. Nat Rev Immunol 20:95-112

Gringhuis SI, Wevers BA, Kaptein TM, van Capel TMM, Theelen B, Boekhout T, de Jong EC, Geijtenbeek TBH (2011) Selective C-Rel activation via Malt1 controls anti-fungal T(H)-17 immunity by dectin-1 and dectin-2. PLoS Pathog 7:e1001259

Gross O, Gewies A, Finger K, Schäfer M, Sparwasser T, Peschel C, Förster I, Ruland J (2006) Card9 controls a non-TLR signalling pathway for innate anti-fungal immunity. Nature 442:651-656

Gross O, Poeck H, Bscheider M, Dostert C, Hannesschläger N, Endres S, Hartmann G, Tardivel A, Schweighoffer E, Tybulewicz V et al (2009) Syk kinase signalling couples to the Nlrp3 inflammasome for anti-fungal host defence. Nature 459:433-436

Grumach AS, de Queiroz-Telles F, Migaud M, Lanternier F, Filho NR, Palma SMU, Constantino-Silva RN, Casanova JL, Puel A (2015) A homozygous CARD9 mutation in a Brazilian patient with deep dermatophytosis. J Clin Immunol 35:486-490

Guo H, Callaway JB, Ting JP-Y (2015) Inflammasomes: mechanism of action, role in disease, and therapeutics. Nat Med 21:677-687

Hailfinger S, Nogai H, Pelzer C, Jaworski M, Cabalzar K, Charton J-E, Guzzardi M, Décaillet C, Grau M, Dörken B et al (2011) Malt1-dependent RelB cleavage promotes canonical NF- $\kappa B$ activation in lymphocytes and lymphoma cell lines. Proc Natl Acad Sci 108:14596-14601

Hara H, Ishihara C, Takeuchi A, Imanishi T, Xue L, Morris SW, Inui M, Takai T, Shibuya A, Saijo $S$ et al (2007) The adaptor protein CARD9 is essential for the activation of myeloid cells through ITAM-associated and Toll-like receptors. Nat Immunol 8:619-629

Hartjes L, Ruland J (2019) CARD9 signaling in intestinal immune homeostasis and oncogenesis. Front Immunol 10:419

Hayden MS, Ghosh S (2012) NF- $\kappa B$, the first quarter-century: remarkable progress and outstanding questions. Genes Dev 26:203-234

He Y, Xu L, Li B, Guo Z-N, Hu Q, Guo Z, Tang J, Chen Y, Zhang Y, Tang J et al (2015) Macrophage-inducible C-type lectin/spleen tyrosine kinase signaling pathway contributes to neuroinflammation after subarachnoid hemorrhage in rats. Stroke 46:2277-2286

He J-J, Ma J, Song H-Q, Zhou D-H, Wang J-L, Huang S-Y, Zhu X-Q (2016) Transcriptomic analysis of global changes in cytokine expression in mouse spleens following acute Toxoplasma gondii infection. Parasitol Res 115:703-712

Heinrich A, Heyl KA, Klaile E, Müller MM, Klassert TE, Wiessner A, Fischer K, Schumann RR, Seifert U, Riesbeck $\mathrm{K}$ et al (2016) Moraxella catarrhalis induces CEACAM3-Syk-CARD9-dependent activation of human granulocytes. Cell Microbiol 18:1570-1582

Holliday MJ, Ferrao R, de Leon Boenig G, Estevez A, Helgason E, Rohou A, Dueber EC, Fairbrother WJ (2018) Picomolar zinc binding modulates formation of Bcl10-nucleating assemblies of the caspase recruitment domain (CARD) of CARD9. J Biol Chem 293:1680316817

Holliday MJ, Witt A, Rodríguez Gama A, Walters BT, Arthur CP, Halfmann R, Rohou A, Dueber EC, Fairbrother WJ (2019) Structures of autoinhibited and polymerized forms of CARD9 reveal mechanisms of CARD9 and CARD11 activation. Nat Commun 10:3070 
Hsu Y-MS, Zhang Y, You Y, Wang D, Li H, Duramad O, Qin X-F, Dong C, Lin X (2007) The adaptor protein CARD9 is required for innate immune responses to intracellular pathogens. Nat Immunol 8:198-205

Huber-Lang M, Lambris JD, Ward PA (2018) Innate immune responses to trauma. Nat Immunol 19:327-341

Hung C-Y, Castro-Lopez N, Cole GT (2016) Card9- and MyD88-mediated gamma interferon and nitric oxide production is essential for resistance to subcutaneous Coccidioides posadasii infection. Infect Immun 84:1166-1175

Imai T, Matsumura T, Mayer-Lambertz S, Wells CA, Ishikawa E, Butcher SK, Barnett TC, Walker MJ, Imamura A, Ishida $\mathrm{H}$ et al (2018) Lipoteichoic acid anchor triggers Mincle to drive protective immunity against invasive group A Streptococcus infection. Proc Natl Acad Sci USA 115:E10662-E10671

Janse M, Lamberts LE, Franke L, Raychaudhuri S, Ellinghaus E, Muri Boberg K, Melum E, Folseraas T, Schrumpf E, Bergquist A et al (2011) Three ulcerative colitis susceptibility loci are associated with primary sclerosing cholangitis and indicate a role for IL2, REL, and CARD9. Hepatol Baltim Md 53:1977-1985

Jeltsch KM, Hu D, Brenner S, Zöller J, Heinz GA, Nagel D, Vogel KU, Rehage N, Warth SC, Edelmann SL et al (2014) Cleavage of roquin and regnase-1 by the paracaspase MALT1 releases their cooperatively repressed targets to promote $\mathrm{T}(\mathrm{H}) 17$ differentiation. Nat Immunol 15:1079-1089

Jhingran A, Mar KB, Kumasaka DK, Knoblaugh SE, Ngo LY, Segal BH, Iwakura Y, Lowell CA, Hamerman JA, Lin X et al (2012) Tracing conidial fate and measuring host cell antifungal activity using a reporter of microbial viability in the lung. Cell Rep. 2:1762-1773

Jhingran A, Kasahara S, Shepardson KM, Junecko BAF, Heung LJ, Kumasaka DK, Knoblaugh SE, Lin X, Kazmierczak BI, Reinhart TA et al (2015) Compartment-specific and sequential role of MyD88 and CARD9 in chemokine induction and innate defense during respiratory fungal infection. PLoS Pathog 11:e1004589

Jia X-M, Tang B, Zhu L-L, Liu Y-H, Zhao X-Q, Gorjestani S, Hsu Y-MS, Yang L, Guan J-H, Xu G-T et al (2014) CARD9 mediates Dectin-1-induced ERK activation by linking Ras-GRF1 to H-Ras for antifungal immunity. J Exp Med 211:2307-2321

Jostins L, Ripke S, Weersma RK, Duerr RH, McGovern DP, Hui KY, Lee JC, Philip Schumm L, Sharma Y, Anderson CA et al (2012) Host-microbe interactions have shaped the genetic architecture of inflammatory bowel disease. Nature 491:119-124

Kalantari P, Morales Y, Miller EA, Jaramillo LD, Ponichtera HE, Wuethrich MA, Cheong C, Seminario MC, Russo JM, Bunnell SC et al (2018) CD209a synergizes with dectin-2 and mincle to drive severe Th17 cell-mediated schistosome egg-induced immunopathology. Cell Rep 22:1288-1300

Kiryluk K, Li Y, Scolari F, Sanna-Cherchi S, Choi M, Verbitsky M, Fasel D, Lata S, Prakash S, Shapiro S et al (2014) Discovery of new risk loci for IgA nephropathy implicates genes involved in immunity against intestinal pathogens. Nat Genet 46:1187-1196

Kiyotake R, Oh-hora M, Ishikawa E, Miyamoto T, Ishibashi T, Yamasaki S (2015) Human Mincle binds to cholesterol crystals and triggers innate immune responses. J Biol Chem 290:2532225332

Klein T, Fung S-Y, Renner F, Blank MA, Dufour A, Kang S, Bolger-Munro M, Scurll JM, Priatel JJ, Schweigler P et al (2015) The paracaspase MALT1 cleaves HOIL1 reducing linear ubiquitination by LUBAC to dampen lymphocyte NF- $\kappa B$ signalling. Nat Commun 6:8777

Lamas B, Richard ML, Leducq V, Pham H-P, Michel M-L, Da Costa G, Bridonneau C, Jegou S, Hoffmann TW, Natividad JM et al (2016) CARD9 impacts colitis by altering gut microbiota metabolism of tryptophan into aryl hydrocarbon receptor ligands. Nat Med 22:598-605

Lamas B, Michel M-L, Waldschmitt N, Pham H-P, Zacharioudaki V, Dupraz L, Delacre M, Natividad JM, Costa GD, Planchais J et al (2018) Card9 mediates susceptibility to intestinal pathogens through microbiota modulation and control of bacterial virulence. Gut 67:18361844 
Lanternier F, Cypowyj S, Picard C, Bustamante J, Lortholary O, Casanova J-L, Puel A (2013) Primary immunodeficiencies underlying fungal infections. Curr Opin Pediatr 25:736-747

Lanternier F, Barbati E, Meinzer U, Liu L, Pedergnana V, Migaud M, Héritier S, Chomton M, Frémond M-L, Gonzales E et al (2015a) Inherited CARD9 deficiency in 2 unrelated patients with invasive exophiala infection. J Infect Dis 211:1241-1250

Lanternier F, Mahdaviani SA, Barbati E, Chaussade H, Koumar Y, Levy R, Denis B, Brunel A-S, Martin S, Loop M et al (2015b) Inherited CARD9 deficiency in otherwise healthy children and adults with Candida species-induced meningoencephalitis, colitis, or both. J Allergy Clin Immunol 135:1558-1568.e2

LeibundGut-Landmann S, Gross O, Robinson MJ, Osorio F, Slack EC, Tsoni SV, Schweighoffer E, Tybulewicz V, Brown GD, Ruland J et al (2007) Syk- and CARD9-dependent coupling of innate immunity to the induction of $\mathrm{T}$ helper cells that produce interleukin 17. Nat Immunol 8:630-638

Leshchiner ES, Rush JS, Durney MA, Cao Z, Dančík V, Chittick B, Wu H, Petrone A, Bittker JA, Phillips A et al (2017) Small-molecule inhibitors directly target CARD9 and mimic its protective variant in inflammatory bowel disease. Proc Natl Acad Sci USA 114:11392-11397

Liu T, Zhang L, Joo D, Sun S-C (2017) NF-кB signaling in inflammation. Signal Transduct Target Ther 2:1-9

Loh JT, Xu S, Huo JX, Kim SS-Y, Wang Y, Lam K-P (2019) Dok3-protein phosphatase 1 interaction attenuates Card9 signaling and neutrophil-dependent antifungal immunity. J Clin Invest 130:2717-2729

MacDuff DA, Reese TA, Baldridge MT, Kimmey JM, Weiss LA, Song C, Nice TJ, Carrero J, Colonna M, Edelson BT et al (2017) Regulation of inflammation, innate immunity and intestinal homeostasis by HOIL1. FASEB J 31:622.1-622.1

Maknitikul S, Luplertlop N, Grau GER, Ampawong S (2017) Dysregulation of pulmonary endothelial protein $\mathrm{C}$ receptor and thrombomodulin in severe falciparum malaria-associated ARDS relevant to hemozoin. PLoS ONE 12:e0181674

Maknitikul S, Luplertlop N, Chaisri U, Maneerat Y, Ampawong S (2018) Featured article: immunomodulatory effect of hemozoin on pneumocyte apoptosis via CARD9 pathway, a possibly retarding pulmonary resolution. Exp Biol Med Maywood NJ 243:395-407

Malik A, Sharma D, Malireddi RKS, Guy CS, Chang T-C, Olsen SR, Neale G, Vogel P, Kanneganti T-D (2018) SYK-CARD9 signaling axis promotes gut fungi-mediated inflammasome activation to restrict colitis and colon cancer. Immunity 49:515-530.e5

Mao L, Zhang L, Li H, Chen W, Wang H, Wu S, Guo C, Lu A, Yang G, An L et al (2014) Pathogenic fungus Microsporum canis activates the NLRP3 inflammasome. Infect Immun 82:882-892

Mao R, Yang R, Chen X, Harhaj EW, Wang X, Fan Y (2017) Regnase-1, a rapid response ribonuclease regulating inflammation and stress responses. Cell Mol Immunol 14:412-422

Marshall ASJ, Willment JA, Lin H-H, Williams DL, Gordon S, Brown GD (2004) Identification and characterization of a novel human myeloid inhibitory C-type lectin-like receptor (MICL) that is predominantly expressed on granulocytes and monocytes. J Biol Chem 279:1479214802

McGovern DPB, Gardet A, Törkvist L, Goyette P, Essers J, Taylor KD, Neale BM, Ong RTH, Lagacé C, Li C et al (2010) Genome-wide association identifies multiple ulcerative colitis susceptibility loci. Nat Genet 42:332-337

Mino T, Murakawa Y, Fukao A, Vandenbon A, Wessels H-H, Ori D, Uehata T, Tartey S, Akira S, Suzuki Y et al (2015) Regnase-1 and Roquin regulate a common element in inflammatory mRNAs by spatiotemporally distinct mechanisms. Cell 161:1058-1073

Monteiro J, Lepenies B (2017) Myeloid C-Type lectin receptors in viral recognition and antiviral immunity. Viruses 9:59

Monteiro JT, Schön K, Ebbecke T, Goethe R, Ruland J, Baumgärtner W, Becker SC, Lepenies B (2019) The CARD9-associated C-type lectin, mincle, recognizes La Crosse Virus (LACV) but plays a limited role in early antiviral responses against LACV. Viruses 11 
Nagata M, Izumi Y, Ishikawa E, Kiyotake R, Doi R, Iwai S, Omahdi Z, Yamaji T, Miyamoto T, Bamba $T$ et al (2017) Intracellular metabolite $\beta$-glucosylceramide is an endogenous Mincle ligand possessing immunostimulatory activity. Proc Natl Acad Sci 114:E3285-E3294

Nagel D, Spranger S, Vincendeau M, Grau M, Raffegerst S, Kloo B, Hlahla D, Neuenschwander M, Peter von Kries J, Hadian K et al (2012) Pharmacologic inhibition of MALT1 protease by phenothiazines as a therapeutic approach for the treatment of aggressive ABC-DLBCL. Cancer Cell 22:825-837

Németh T, Futosi K, Sitaru C, Ruland J, Mócsai A (2016) Neutrophil-specific deletion of the CARD9 gene expression regulator suppresses autoantibody-induced inflammation in vivo. Nat Commun 7:11004

Oeckinghaus A, Wegener E, Welteke V, Ferch U, Arslan SC, Ruland J, Scheidereit C, Krappmann D (2007) Malt1 ubiquitination triggers NF-kappaB signaling upon T-cell activation. EMBO J 26:4634-4645

Ostrop J, Jozefowski K, Zimmermann S, Hofmann K, Strasser E, Lepenies B, Lang R (2015) Contribution of MINCLE-SYK signaling to activation of primary human APCs by mycobacterial cord factor and the novel adjuvant TDB. J Immunol Baltim Md 1950 (195):2417-2428

Pandori WJ, Lima TS, Mallya S, Kao TH, Gov L, Lodoen MB (2019) Toxoplasma gondii activates a Syk-CARD9-NF- $\mathrm{BB}$ signaling axis and gasdermin D-independent release of IL-1 $\beta$ during infection of primary human monocytes. PLoS Pathog 15:e1007923

Phongsisay V, Iizasa E, Hara H, Yoshida H (2015) Evidence for TLR4 and FcR $\gamma$-CARD9 activation by cholera toxin B subunit and its direct bindings to TREM2 and LMIR5 receptors. Mol Immunol 66:463-471

Poeck H, Bscheider M, Gross O, Finger K, Roth S, Rebsamen M, Hannesschläger N, Schlee M, Rothenfusser S, Barchet W et al (2010) Recognition of RNA virus by RIG-I results in activation of CARD9 and inflammasome signaling for interleukin $1 \beta$ production. Nat Immunol 11:63-69

Pointon JJ, Harvey D, Karaderi T, Appleton LH, Farrar C, Stone MA, Sturrock RD, Brown MA, Wordsworth BP (2010) Elucidating the chromosome 9 association with AS; CARD9 is a candidate gene. Genes Immun 11:490-496

Qin X, Peterson MR, Haller SE, Cao L, Thomas DP, He G (2018) Caspase recruitment domain-containing protein 9 (CARD9) knockout reduces regional ischemia/reperfusion injury through an attenuated inflammatory response. PLoS ONE 13:e199711

Qu J, Liu L, Xu Q, Ren J, Xu Z, Dou H, Shen S, Hou Y, Mou Y, Wang T (2019) CARD9 prevents lung cancer development by suppressing the expansion of myeloid-derived suppressor cells and IDO production. Int $\mathrm{J}$ Cancer

Queiroz-Telles F, Mercier T, Maertens J, Sola CBS, Bonfim C, Lortholary O, Constantino-Silva RMN, Schrijvers R, Hagen F, Meis JF et al (2019) Successful allogenic stem cell transplantation in patients with inherited CARD9 deficiency. J Clin Immunol 39:462-469

Redelinghuys P, Brown GD (2011) Inhibitory C-type lectin receptors in myeloid cells. Immunol Lett 136:1-12

Rieber N, Singh A, Öz H, Carevic M, Bouzani M, Amich J, Ost M, Ye Z, Ballbach M, Schäfer I et al (2015) Pathogenic fungi regulate immunity by inducing neutrophilic myeloid-derived suppressor cells. Cell Host Microbe 17:507-514

Ritter M, Gross O, Kays S, Ruland J, Nimmerjahn F, Saijo S, Tschopp J, Layland LE, Prazeres da Costa C (2010) Schistosoma mansoni triggers Dectin-2, which activates the Nlrp3 inflammasome and alters adaptive immune responses. Proc Natl Acad Sci 107:20459-20464

Rivas MA, Beaudoin M, Gardet A, Stevens C, Sharma Y, Zhang CK, Boucher G, Ripke S, Ellinghaus D, Burtt N et al (2011) Deep resequencing of GWAS loci identifies independent rare variants associated with inflammatory bowel disease. Nat Genet 43:1066-1073

Rivera A, Siracusa MC, Yap GS, Gause WC (2016) Innate cell communication kick-starts pathogen-specific immunity. Nat Immunol 17:356-363 
Robinson MJ, Osorio F, Rosas M, Freitas RP, Schweighoffer E, Gross O, Verbeek JS, Ruland J, Tybulewicz V, Brown GD et al (2009) Dectin-2 is a Syk-coupled pattern recognition receptor crucial for Th17 responses to fungal infection. J Exp Med 206:2037-2051

Rogers NC, Slack EC, Edwards AD, Nolte MA, Schulz O, Schweighoffer E, Williams DL, Gordon S, Tybulewicz VL, Brown GD et al (2005) Syk-dependent cytokine induction by Dectin-1 reveals a novel pattern recognition pathway for C type lectins. Immunity 22:507-517

Roth S, Ruland J (2013) Caspase recruitment domain-containing protein 9 signaling in innate immunity and inflammation. Trends Immunol 34:243-250

Roth S, Rottach A, Lotz-Havla AS, Laux V, Muschaweckh A, Gersting SW, Muntau AC, Hopfner K-P, Jin L, Vanness K et al (2014) Rad50-CARD9 interactions link cytosolic DNA sensing to IL-1 $\beta$ production. Nat Immunol 15:538-545

Roth S, Bergmann H, Jaeger M, Yeroslaviz A, Neumann K, Koenig P-A, Prazeres da Costa C, Vanes L, Kumar V, Johnson M et al (2016) Vav proteins are key regulators of Card9 signaling for innate antifungal immunity. Cell Rep 17:2572-2583

Ruland J, Hartjes L (2019) CARD-BCL-10-MALT1 signalling in protective and pathological immunity. Nat Rev Immunol 19:118-134

Saijo S, Ikeda S, Yamabe K, Kakuta S, Ishigame H, Akitsu A, Fujikado N, Kusaka T, Kubo S, Chung $S$ et al (2010) Dectin-2 recognition of alpha-mannans and induction of Th17 cell differentiation is essential for host defense against Candida albicans. Immunity 32:681-691

Sato K, Yang X, Yudate T, Chung J-S, Wu J, Luby-Phelps K, Kimberly RP, Underhill D, Cruz PD, Ariizumi K (2006) Dectin-2 is a pattern recognition receptor for fungi that couples with the $\mathrm{Fc}$ receptor gamma chain to induce innate immune responses. J Biol Chem 281:38854-38866

Schweneker K, Gorka O, Schweneker M, Poeck H, Tschopp J, Peschel C, Ruland J, Gross O (2013) The mycobacterial cord factor adjuvant analogue trehalose-6,6'-dibehenate (TDB) activates the Nlrp3 inflammasome. Immunobiology 218:664-673

Seifert L, Werba G, Tiwari S, Giao Ly NN, Alothman S, Alqunaibit D, Avanzi A, Barilla R, Daley D, Greco SH et al (2016) The necrosome promotes pancreatic oncogenesis via CXCL1 and Mincle-induced immune suppression. Nature 532:245-249

Shenderov K, Barber DL, Mayer-Barber KD, Gurcha SS, Jankovic D, Feng CG, Oland S, Hieny S, Caspar P, Yamasaki S et al (2013) Cord factor and peptidoglycan recapitulate the Th17-promoting adjuvant activity of mycobacteria through mincle/CARD9 signaling and the inflammasome. J Immunol Baltim Md 1950(190):5722-5730

Sokol H, Conway KL, Zhang M, Choi M, Morin B, Cao Z, Villablanca EJ, Li C, Wijmenga C, Yun SH et al (2013) Card9 mediates intestinal epithelial cell restitution, T-helper 17 responses, and control of bacterial infection in mice. Gastroenterology 145:591-601.e3

Staal J, Driege Y, Haegman M, Borghi A, Hulpiau P, Lievens L, Gul IS, Sundararaman S, Gonçalves A, Dhondt I et al (2018) Ancient origin of the CARD-coiled coil/Bcl10/ MALT1-like paracaspase signaling complex indicates unknown critical functions. Front Immunol 9:1136

Strasser D, Neumann K, Bergmann H, Marakalala MJ, Guler R, Rojowska A, Hopfner K-P, Brombacher F, Urlaub H, Baier G et al (2012) Syk kinase-coupled C-type lectin receptors engage protein kinase $C-\sigma$ to elicit Card 9 adaptor-mediated innate immunity. Immunity $36: 32$ 42

Sun L, Deng L, Ea C-K, Xia Z-P, Chen ZJ (2004) The TRAF6 ubiquitin ligase and TAK1 kinase mediate IKK activation by BCL10 and MALT1 in T lymphocytes. Mol Cell 14:289-301

Tartey S, Gurung P, Samir P, Burton A, Kanneganti T-D (2018) Cutting edge: dysregulated CARD9 signaling in neutrophils drives inflammation in a mouse model of neutrophilic dermatoses. J Immunol Baltim Md 1950(201):1639-1644

Taylor PR, Tsoni SV, Willment JA, Dennehy KM, Rosas M, Findon H, Haynes K, Steele C, Botto M, Gordon S et al (2007) Dectin-1 is required for beta-glucan recognition and control of fungal infection. Nat Immunol 8:31-38 
Thiagarajan PS, Yakubenko VP, Elsori DH, Yadav SP, Willard B, Tan CD, René Rodriguez E, Febbraio M, Cathcart MK (2013) Vimentin is an endogenous ligand for the pattern recognition receptor Dectin-1. Cardiovasc Res 99:494-504

Thiem K, Hoeke G, van den Berg S, Hijmans A, Jacobs CWM, Zhou E, Mol IM, Mouktaroudi M, Bussink J, Kanneganti TD et al (2019) Deletion of hematopoietic Dectin-2 or CARD9 does not protect against atherosclerotic plaque formation in hyperlipidemic mice. Sci Rep 9:4337

Uehata T, Iwasaki H, Vandenbon A, Matsushita K, Hernandez-Cuellar E, Kuniyoshi K, Satoh T, Mino T, Suzuki Y, Standley DM et al (2013) Malt1-induced cleavage of regnase-1 in CD4(+) helper $\mathrm{T}$ cells regulates immune activation. Cell 153:1036-1049

Uematsu T, Iizasa E, Kobayashi N, Yoshida H, Hara H (2015) Loss of CARD9-mediated innate activation attenuates severe influenza pneumonia without compromising host viral immunity. Sci Rep 5:17577

Uren AG, O'Rourke K, Aravind LA, Pisabarro MT, Seshagiri S, Koonin EV, Dixit VM (2000) Identification of paracaspases and metacaspases: two ancient families of caspase-like proteins, one of which plays a key role in MALT lymphoma. Mol Cell 6:961-967

Wang C, Deng L, Hong M, Akkaraju GR, Inoue J, Chen ZJ (2001) TAK1 is a ubiquitin-dependent kinase of MKK and IKK. Nature 412:346-351

Wang S-F, Huang JC, Lee Y-M, Liu S-J, Chan Y-J, Chau Y-P, Chong P, Chen Y-MA (2008) DC-SIGN mediates avian H5N1 influenza virus infection in cis and in trans. Biochem Biophys Res Commun 373:561-566

Wang X, Wang W, Lin Z, Wang X, Li T, Yu J, Liu W, Tong Z, Xu Y, Zhang J et al (2014) CARD9 mutations linked to subcutaneous phaeohyphomycosis and TH17 cell deficiencies. J Allergy Clin Immunol 133:905-908.e3

Wang T, Fan C, Yao A, Xu X, Zheng G, You Y, Jiang C, Zhao X, Hou Y, Hung M-C et al (2018) The adaptor protein CARD9 protects against colon cancer by restricting mycobiota-mediated expansion of myeloid-derived suppressor cells. Immunity 49:504-514.e4

Werninghaus K, Babiak A, Gross O, Hölscher C, Dietrich H, Agger EM, Mages J, Mocsai A, Schoenen H, Finger K et al (2009) Adjuvanticity of a synthetic cord factor analogue for subunit Mycobacterium tuberculosis vaccination requires FcRgamma-Syk-Card9-dependent innate immune activation. J Exp Med 206:89-97

Wirnsberger G, Zwolanek F, Asaoka T, Kozieradzki I, Tortola L, Wimmer RA, Kavirayani A, Fresser F, Baier G, Langdon WY et al (2016) Inhibition of CBLB protects from lethal Candida albicans sepsis. Nat Med 22:915-923

Wu W, Hsu Y-MS, Bi L, Songyang Z, Lin X (2009) CARD9 facilitates microbe-elicited production of reactive oxygen species by regulating the LyGDI-Rac1 complex. Nat Immunol 10:1208-1214

Wu W, Zhang R, Wang X, Song Y, Liu Z, Han W, Li R (2016) Impairment of immune response against dematiaceous fungi in Card9 knockout mice. Mycopathologia 181:631-642

Xiao Y, Tang J, Guo H, Zhao Y, Tang R, Ouyang S, Zeng Q, Rappleye CA, Rajaram MVS, Schlesinger LS et al (2016) Targeting CBLB as a potential therapeutic approach for disseminated candidiasis. Nat Med 22:906-914

Xu X, Xu J-F, Zheng G, Lu H-W, Duan J-L, Rui W, Guan J-H, Cheng L-Q, Yang D-D, Wang M-C et al (2018) CARD9S12N facilitates the production of IL-5 by alveolar macrophages for the induction of type 2 immune responses. Nat Immunol 19:547-560

Xu P, Zhang X, Liu Q, Xie Y, Shi X, Chen J, Li Y, Guo H, Sun R, Hong Y et al (2019) Microglial TREM-1 receptor mediates neuroinflammatory injury via interaction with SYK in experimental ischemic stroke. Cell Death Dis 10:555

Yamamoto H, Nakamura Y, Sato K, Takahashi Y, Nomura T, Miyasaka T, Ishii K, Hara H, Yamamoto N, Kanno E et al (2014) Defect of CARD9 leads to impaired accumulation of gamma interferon-producing memory phenotype $\mathrm{T}$ cells in lungs and increased susceptibility to pulmonary infection with Cryptococcus neoformans. Infect Immun 82:1606-1615

Yamasaki S, Ishikawa E, Sakuma M, Hara H, Ogata K, Saito T (2008) Mincle is an ITAM-coupled activating receptor that senses damaged cells. Nat Immunol 9:1179-1188 
Yan J, Wu B, Huang B, Huang S, Jiang S, Lu F (2014) Dectin-1-CD37 association regulates IL-6 expression during Toxoplasma gondii infection. Parasitol Res 113:2851-2860

Yang H, Minamishima YA, Yan Q, Schlisio S, Ebert BL, Zhang X, Zhang L, Kim WY, Olumi AF, Kaelin WG (2007) pVHL acts as an adaptor to promote the inhibitory phosphorylation of the NF-kappaB agonist Card9 by CK2. Mol Cell 28:15-27

Yang C-S, Rodgers M, Min C-K, Lee J-S, Kingeter L, Lee J-Y, Jong A, Kramnik I, Lin X, Jung JU (2012) The autophagy regulator Rubicon is a feedback inhibitor of CARD9-mediated host innate immunity. Cell Host Microbe 11:277-289

Yang M, Shao J-H, Miao Y-J, Cui W, Qi Y-F, Han J-H, Lin X, Du J (2014) Tumor cell-activated CARD9 signaling contributes to metastasis-associated macrophage polarization. Cell Death Differ 21:1290-1302

Yang Y, Kelly P, Shaffer AL, Schmitz R, Yoo HM, Liu X, Huang DW, Webster D, Young RM, Nakagawa $M$ et al (2016a) Targeting non-proteolytic protein ubiquitination for the treatment of diffuse large B cell lymphoma. Cancer Cell 29:494-507

Yang Y-K, Yang C, Chan W, Wang Z, Deibel KE, Pomerantz JL (2016b) Molecular determinants of scaffold-induced linear ubiquitinylation of B cell lymphoma/leukemia 10 (Bcl10) during T cell receptor and oncogenic caspase recruitment domain-containing protein 11 (CARD11) signaling. J Biol Chem 291:25921-25936

Yang Z, Weng C, Wang J, Xu P (2016c) The role of Card9 overexpression in peripheral blood mononuclear cells from patients with aseptic acute pancreatitis. J Cell Mol Med 20:441-449

Yang Z-W, Meng X-X, Zhang C, Xu P (2017) CARD9 gene silencing with siRNA protects rats against severe acute pancreatitis: CARD9-dependent NF- $\kappa B$ and P38MAPKs pathway. J Cell Mol Med 21:1085-1093

Yu JW, Hoffman S, Beal AM, Dykon A, Ringenberg MA, Hughes AC, Dare L, Anderson AD, Finger J, Kasparcova V et al (2015) MALT1 protease activity is required for innate and adaptive immune responses. PLoS ONE 10:e127083

Zhang Q, Cao X (2019) Epigenetic regulation of the innate immune response to infection. Nat Rev Immunol 19:417-432

Zhang M, Lee AJ, Wu X, Sun S-C (2011) Regulation of antiviral innate immunity by deubiquitinase CYLD. Cell Mol Immunol 8:502-504

Zhernakova A, Festen EM, Franke L, Trynka G, van Diemen CC, Monsuur AJ, Bevova M, Nijmeijer RM, van't Slot R, Heijmans R et al (2008) Genetic analysis of innate immunity in Crohn's disease and ulcerative colitis identifies two susceptibility loci harboring CARD9 and IL18RAP. Am J Hum Genet 82:1202-1210

Zhong X, Chen B, Yang L, Yang Z (2019) Card9 as a critical regulator of tumor development. Cancer Lett 451:150-155

Zhu L-L, Zhao X-Q, Jiang C, You Y, Chen X-P, Jiang Y-Y, Jia X-M, Lin X (2013) C-type lectin receptors dectin-3 and dectin-2 form a heterodimeric pattern-recognition receptor for host defense against fungal infection. Immunity 39:324-334 